\title{
Sickle cell disease complications
}

\author{
Ersi Voskaridou \\ Thalassaemia Unit, 'Laiko' General Hospital, Athens, Greece
}

\begin{abstract}
Sickle cell disease (SCD) is an inherited, lifelong condition. The sickle mutation consists a single nucleotide change (GAT- $>$ GTT) in the sixth codon of exon 1 of the $\beta$-globin gene coding for the $\beta$-globin polypeptide of hemoglobin $(\mathrm{Hb})\left(\alpha_{2} \beta_{2}\right)$. This change results in replacement of the wild type glutamic acid residue by a valine residue in $\beta$-globin chain and the formation of the sickle $\mathrm{Hb}(\mathrm{HbS})$ in homozygotes for this mutation. Heterozygotes live a normal life. In SCD patients, sickle erythrocytes are rigid with decreased deformability and reduced life span resulting in hemolysis, vaso-occlusive disease, vasculopathy and subsequent inflammation and end organ damage. Sickle cell disease affects millions of people worldwide. Today, with proper health care, many SCD patients have a good quality of life $(\mathrm{Q} o \mathrm{~L})$ and are in fairly good health most of the time. These people can live up to their forties or fifties, or longer. Despite the 'common' underlying genetic basis and a similar pathophysiology, patients with SCD present a highly variable clinical phenotype due to Single Nucleotide Polymorphisms (SNPs) variability throughout the genome. Patients with SCD are at high risk for developing multisystem acute and chronic complications associated with significant morbidity and mortality.
\end{abstract}

\section{Acute complications of sickle cell disease}

The most common complication of SCD is an acute episode of severe pain referred to as an acute vaso-occlusive crisis (VOC). A VOC is defined as pain resulting from tissue ischemia caused by vaso-occlusion most commonly in the bone(s) and bone marrow. ther common acute complications of SCD include fever related to infection, acute renal failure, hepatobiliary complications, acute anemia, splenic sequestration, acute chest syndrome (ACS), and acute stroke.

Correspondence: Ersi Voskaridou, Thalassaemia Unit, 'Laiko' General Hospital, Athens, Greece

E-mail: ersi_voskaridou@yahoo.com; ersi.voskaridou@gmail.com

Key words: sickle cell disease; $\beta$-globin; hemoglobin; homozygotes.

(C) Copyright Ersi Voskaridou, 2014

Licensee PAGEPress, Italy

Thalassemia Reports 2014; $4: 4873$

doi:10.4081/thal.2014.4873

This article is distributed under the terms of the Creative Commons Attribution Noncommercial License (by-nc 3.0) which permits any noncommercial use, distribution, and reproduction in any medium, provided the original author(s) and source are credited.

\section{Vaso-occlusive crisis (VOC) or sickle cell crisis}

A VOC is the hallmark acute complication for SCD and manifests as acute severe pain. The sickled erythrocytes block the flow of blood through the small blood vessels (capillaries) resulting in ischemia. Sudden episodes of pain throughout the body are a common symptom of SCD. This sudden pain can range from mild to very severe form and usually lasts from hours to a few days. VOCs and their accompanying pain most commonly occur in the extremities, chest, and back. When they occur in other sites, they can be confused with, or can be the prodromal stage of, other acute complications (e.g., head (stroke), flank (papillary necrosis), and abdomen (hepatic or splenic sequestration, constipation from opioid toxicity, or another hepatobiliary complication). Patients with more than three hospitalizations for a VOC in a year are considered to be at an increased risk of early death.,

\section{Hand-foot syndrome}

When sickle cells block the small blood vessels at hands or feet, pain and swelling along with fever may occur. The first VOC may appear as early as at 6 months of age, often presenting as dactylitis, but thereafter VOCs occur with variable frequency. This may be the first sign of sickle cell anemia in infants. ${ }^{2}$

\section{Fever-infections}

Patients with SCD have an increased risk for severe bacterial infection, resulting primarily from reduced or absent splenic function. ${ }^{3}$ The result is an extremely high risk of septicemia and meningitis, primarily due to Streptococcus pneumoniae. The risk of such infections continues throughout childhood and to a lesser extent in adults. Fever, as a presenting symptom, heralds many acute and sometimes life-threatening conditions, such as ACS and osteomyelitis. It is critical that fever alone is taken seriously in these patients and considered a potential emergency situation. Fever associated with pain should not be considered a VOC until infection is ruled out. Acute osteomyelitis, another complication associated with fever, may be unifocal or multifocal and may be caused by Staphylococcus aureus, salmonella, or other enteric pathogens. Pneumonia is the most common cause of death in young children with sickle cell disease. Meningitis, influenza, and hepatitis are other infections that are common in people with sickle cell disease.

\section{Acute renal failure}

Acute renal failure is defined as a rapid reduction in renal function manifested by a rise in serum creatinine and reduction in glomerular filtration rate (GFR), with or without a decline in urine output. Acute renal failure may be due to pre-renal (e.g., dehydration) or post-renal (e.g., obstruction) insults, or result from intrinsic renal disease (e.g., glomerular injury). It may occur during an acute VOC, most often in association with ACS or acute multisystem organ failure. Renal papillary necrosis due to medullary infarction from obstruction of the blood supply in the vasa recta affects up to $15-30$ percent of individuals with SCD. ${ }^{4}$ Signs and symptoms include pain and hematuria. When present, fever suggests possible infection. The serum creatinine levels are gen- 
erally low or low-normal in patients with SCD and the values in acute renal function may still be within normal limits even if serum creatinine level increase two times from baseline.

\section{Hepatobiliary complications}

Biliary tract abnormalities are common in SCD patients. These abnormalities include cholelithiasis, acute cholecystitis, biliary sludge, and acute choledocholithiasis. Hemolysis of any etiology results in increased secreted unconjugated bilirubin that tends to precipitate and leads to gallstones and sludge.

\section{Acute hepatic sequestration}

Sequestration of red blood cells in the liver often develops over a few hours to a few days, and the resultant stretching of the hepatic capsule is usually painful.

\section{Acute intrahepatic cholestasis}

Acute intrahepatic cholestasis (also called sickle cell hepatopathy or "drepanocyte" liver) is also associated with SCD. It is characterized by the sudden onset of pain, increasing jaundice, a progressively enlarging and extremely tender liver, light-colored stools, and extreme hyperbilirubinemia (both conjugated and unconjugated). This complication may prove fatal if not recognized and treated promptly. ${ }^{5}$

\section{Acute anemia}

Acute anemia, defined as a decline in hemoglobin concentration by $2.0 \mathrm{~g} / \mathrm{dL}$ or more below the patient's baseline value, may have diverse etiologies. Therefore, splenic sequestration in a child or an aplastic episode at any age may require urgent evaluation and therapy. The reticulocyte count is an important index to assess diminished red blood cell production (low reticulocyte count, as can occur in parvovirus infected individuals, results in aplastic crisis), accelerated hemolysis, or sequestration in the lungs, spleen, or liver. An aplastic crisis is a common feature of SCD, especially in childhood. ${ }^{6}$ The usual clinical picture is gradual onset of fatigue, shortness of breath, and sometimes syncope. Fever is quite common as well. Parvovirus B19 is the most common cause.

\section{Splenic sequestration}

Splenic sequestration is defined as sudden enlargement of the spleen and reduction in hemoglobin concentration by at least $2 \mathrm{~g} / \mathrm{dL}$ below the baseline value. It is a major cause of acute anemia and it may present acutely accompanied by severe anemia and hypovolemic shock. The reticulocyte count and circulating nucleated red blood cells are usually elevated.

\section{Acute chest syndrome (ACS)}

Acute chest syndrome is a life-threatening condition for SCD patients. ${ }^{7}$ It is the second most frequent reason for hospitalization in children and adults with SCD and the most common cause of death. It's similar to pneumonia and is caused by an infection or by sickle cells trapped in the lungs. Patients with this condition usually have chest pain, fever, and an abnormal chest $x$ ray. Over time, lung damage may lead to pulmonary hypertension.

\section{Acute stroke}

Stroke is one of the most common and devastating complications of SCD. ${ }^{8}$ Sickle-shaped red blood cells may stick to the walls of the tiny blood vessels in the brain. This type of stroke occurs mainly in children. This complication presents as sudden onset of weakness, aphasia, and sometimes seizures or coma and results in adverse motor and cognitive sequelae. In the absence of secondary prevention measures such as a chronic transfusion program or hematopoietic stem cell transplanta- tion, recurrence rates have been shown to range between 46 and 90 percent in children with SCD. ${ }^{9}$ Brain hemorrhage occurs more often in adults patients.

\section{Priapism}

Males with sickle cell disease may have painful and unwanted erections lasting about 4 hours, called priapism. This happens because the sickle cells stop blood flow out of an erect penis. Priapism is a common complication of SCD, affecting 35 percent of male patients. ${ }^{10}$ Over time, priapism can damage the penis and lead to impotence.

\section{Multisystem organ failure}

Multisystem organ failure is a severe, rare and life-threatening complication usually associated with a VOC and characterized by failure of the lungs, liver, and/or kidneys. ${ }^{11}$ Symptoms linked to this complication are fever and changes in mental status such as sudden tiredness and loss of interest in their surroundings.

\section{Chronic complications of sickle cell disease}

The incidence of chronic complications appears to increase with age and understanding of the pathophysiology and the involved factors is necessary to prevent or reduce long-term morbidity.

\section{Chronic pain}

In SCD, pain is considered chronic if it persists more than 3 months. Chronic pain may be an extension of recurrent acute painful episodes or in a specific tissue or organ, such as avascular necrosis of the hips, or leg ulcers. Chronic pain is often associated with other conditions that enhance its chronicity. These include psychosocial factors such as depression, anxiety, feelings of despair, insomnia, loneliness, helplessness and dependence on pain medications. ${ }^{12}$ Chronic pain can be hard and may lead in mental draining.

\section{Avascular necrosis}

Avascular or aseptic necrosis can occur when capillaries are occluded by sickled erythrocytes at distal portions of a bone, near a joint, where hypoxia is maximal and collateral circulation is inadequate. ${ }^{13}$ The femoral neck is the most common site of aseptic necrosis. It causes chronic severe pain and disability.

\section{Leg ulcers}

Leg ulcers are a common complication of SCD. ${ }^{14}$ Sickle cell ulcers usually begin as small sores on the lower third of the leg. Leg ulcers occur more often in males than in females and usually appear between the ages of 10 and 50. The cause of leg ulcers is not clear. Some heal rapidly, but others persist for years or recur.

\section{Pulmonary hypertension}

Pulmonary hypertension $(\mathrm{PH})$ is defined as an elevation of the resting mean pulmonary arterial pressure $(>25 \mathrm{mmHg})$ as determined by right heart catheterization (RHC) (15). PH can occur in chronic hemolytic anemia and in the setting of chronic lung disease, chronic thromboembolic disease, or can be due to unclear and multiple mechanisms. Initial testing for PH has been done with an echocardiography assessment to estimate pulmonary artery pressure using tricuspid regurgitant jet velocity (TRV), but diagnosis requires right heart catheterization and direct measurement of the pulmonary arterial pressure and vaso-reactivity of the vessels. ${ }^{15}$ Excessive shortness of breath is an important symptom of $\mathrm{PH}$. 


\section{Renal complications}

Identification of early renal disease in people with SCD is important, as these patients hyper secrete creatinine through the proximal tubules, thus masking significant renal impairment before the serum creatinine rises. ${ }^{16}$ Microalbuminuria is most often the first manifestation of chronic kidney disease in SCD. Proteinuria due to glomerular injury is also common, but both microalbuminuria and macroalbuminuria are typically asymptomatic. The most common renal complication in people with SCD is hyposthenuria, or the inability to concentrate the urine, which is progressive with age. ${ }^{17}$

\section{Stuttering/recurrent priapism}

Stuttering priapism is the occurrence of multiple self-limited episodes of unwanted, often painful erections lasting more than 4 hours. ${ }^{10}$ Priapism, including stuttering priapism, is common, affecting 35 percent of male SCD patients.

\section{Ophthalmologic complications}

Chronic ophthalmological complications of SCD include proliferative sickle retinopathy and vitreous hemorrhage. They occur in up to 50 percent of patients with SCD and are associated with significant visual loss. ${ }^{18}$

\section{Current therapy for sickle cell disease}

- Symptomatic for painful crises

- Hydroxyurea for painful crises

- Transfusions for severe anemia

- Exchange transfusion for CNS events, chest syndrome, pulmonary hypertension

- Folate prophylaxis

- Allogeneic marrow transplantation, experimental/future therapy for sickle cell disease

- Other agents increasing fetal hemoglobin

- Anti-sickling drugs

- Globin gene therapy

\section{References}

1. Platt OS, Brambilla DJ, Rosse WF, et al. Mortality in sickle cell disease. Life expectancy and risk factors for early death. N Engl J Med 1994;330:1639-44.
2. Ballas SK, Lusardi M. Hospital readmission for adult acute sickle cell painful episodes: frequency, etiology, and prognostic significance. Am J Hematol 2005;79:17-25.

3. Booth $\mathrm{C}$, Inusa B, Obaro SK. Infection in sickle cell disease: a review. Int J Infect Dis 2010;14:e2-e12.

4. Pham PT, Pham PC, Wilkinson AH, Lew SQ. Renal abnormalities in sickle cell disease. Kidney Int 2000;57:1-8.

5. Shao SH, Orringer EP. Sickle cell intrahepatic cholestasis: approach to a difficult problem. Am J Gastroenterol 1995;90:2048-50.

6. Smith-Whitley K, Zhao H, Hodinka RL, et al. Epidemiology of human parvovirus B19 in children with sickle cell disease. Blood 2004;103:422-7.

7. Vichinsky EP, Neumayr LD, Earles AN, et al. Causes and outcomes of the acute chest syndrome in sickle cell disease. National Acute Chest Syndrome Study Group. N Engl J Med 2000;342:1855-65.

8. Ohene-Frempong K, Weiner SJ, Sleeper LA, et al. Cerebrovascular accidents in sickle cell disease: rates and risk factors Blood 1998;91:288-94.

9. Verduzco LA, Nathan DG. Sickle cell disease and stroke. Blood 2009;114:5117-25.

10. Olujohungbe AB, Adeyoju A, Yardumian A, et al. A prospective diary study of stuttering priapism in adolescents and young men with sickle cell anemia: report of an international randomized control trial - The Priapism in Sickle Cell Study. J Androl 2011;32:375-82.

11. Hassell KL, Eckman JR, Lane PA. Acute multiorgan failure syndrome: a potentially catastrophic complication of severe sickle cell pain episodes. Am J Med 1994;96:155-62.

12. Serjeant DR, Serjeant BE. Sickle cell disease. New York: Oxford University Press; 2001.

13. Diggs LW. Bone and joint lesions in sickle-cell disease. Clin Orthop Relat Res 1967;52:119-43.

14. Mason VR. Sickle cell anemia. J Am Med Assoc 1922;79:1318-20.

15. Badesch DB, Champion HC, Sanchez MA, et al. Diagnosis and assessment of pulmonary arterial hypertension. J Am Coll Cardiol 2009;54:S55-66.

16. Ataga KI, Orringer EP. Renal abnormalities in sickle cell disease. Am J Hematol 2000;63:205-11.

17. Francis YF, Worthen HG. Hyposthenuria in sickle cell disease. J Natl Med Assoc 1968;60:266-70.

18. Moriarty BJ, Acheson RW, Condon PI, Serjeant GR. Patterns of visual loss in untreated sickle cell retinopathy. Eye (Lond) $1988 ; 2$ (Pt 3):330-5. 